\title{
Nutritional Supplements and the Brain
}

\author{
Romain Meeusen and Lieselot Decroix \\ Vrije Universiteit Brussel
}

\begin{abstract}
Cognitive function plays an important role in athletic performance, and it seems that brain functioning can be influenced by nutrition and dietary components. Thus, the central nervous system might be manipulated through changes in diet or supplementation with specific nutrients including branched-chain amino acids, tyrosine, carbohydrates, and caffeine. Despite some evidence that branched-chained amino acids can influence ratings of perceived exertion and mental performance, several well-controlled studies have failed to demonstrate a positive effect on exercise performance. Evidence of an ergogenic benefit of tyrosine supplementation during prolonged exercise is limited. There is evidence that mild dehydration can impair cognitive performance and mood. The beneficial effect of carbohydrate supplementation during prolonged exercise could relate to increased substrate delivery for the brain, with numerous studies indicating that hypoglycemia affects brain function and cognitive performance. Caffeine can enhance performance and reduce perception of effort during prolonged exercise and will influence specific reward centers of the brain. Plant products and herbal extracts such as polyphenols, ginseng, ginkgo biloba, etc. are marketed as supplements to enhance performance. In several animal studies, positive effects of these products were shown, however the literature on their effects on sports performance is scarce. Polyphenols have the potential to protect neurons against injury induced by neurotoxins, suppress neuroinflammation, and to promote memory, learning, and cognitive function. In general, there remains a need for controlled randomized studies with a strong design, sufficient statistical power, and well-defined outcome measures before "claims" on its beneficial effects on brain functioning can be established.
\end{abstract}

Keywords: cognitive function, exercise, nutrition, supplementation

Thinking about food can modulate neural activity in specific brain areas known to be involved in the cognitive controls of appetitive behaviors. This leads to saliva production, gastric acid, and insulin secretion (Berthoud, 2007). When food is encountered, smell and taste act as additional stimuli to recall memorial representations of experiences with particular food items. These memorial representations can be pleasant or unpleasant (e.g., conditioned food/taste aversion). It is clear that nutrition (and supplements) will influence brain functioning. Nutrition provides the proper building blocks for the brain to create and maintain connections, which is critical for improved cognition and academic performance. Dietary factors have a broad and positive action on neuronal function and plasticity. For example, the omega-3 fatty acids, which are typically found in high concentrations in algae and fish, provide building material to the brain. Diets rich in sugar, saturated fats, or high in calories are considered deleterious for neural function, as they act to elevate levels of oxidative stress and to reduce synaptic plasticity and cognitive functions (Gomez-Pinilla, 2011). Brain function is certainly dependent on adequate nutrition, and shortterm variations in the amount and composition of nutrient intake in healthy individuals influence measures of cognitive function (Meeusen, 2014).

There is increasing interest in examining the possible influence of supplements on exercise performance, especially endurance performance. However, it is clear that performance in many sports also involves high-intensity exercise which includes immediate decision making and skill accuracy. Sports performance depends

Meeusen and Decroix are with the Human Physiology Research Group, Faculty LK, Vrije Universiteit Brussel, Brussels, Belgium. Address author correspondence to Romain Meeusen at romain.meeusen@vub.be. on the interaction of the brain with the periphery. Motor control, decision making, coordination, reaction time, and other cognitive tasks can be essential during several sports, including team sports. However, fatigue does not only occur at the peripheral level, but "central" fatigue or "mental" fatigue exist, involving brain mechanisms. Cognitive function plays an important role in athletic performance, and it seems that brain functioning can be influenced by nutrition (Meeusen, 2014). This paper will focus on the putative effects of dietary supplements on brain functioning during exercise.

\section{How to Measure Cognitive Performance in Sports?}

In many team sports, or so-called "open skill sports", players need to react in a dynamically-changing, unpredictable, and externallypaced environment (Huijgen et al., 2015). These sports need strong visual attention and executive function and rely on working memory for decision making (Pesce et al., 2007). Cognitive flexibility and inhibitory control are necessary for passing, making decisions on how to dribble, and so on. Literature on the influence of fatigue on cognitive performance shows that both mental fatigue and physical fatigue can impair performance on a cognitive task or a sport-specific performance (Goble \& Christy, 2017). Most of the cognitive abilities are tested in standardized situations or computerized tests, and therefore the results on these tests are not always transferrable to "real-life" sports situations. Several studies used more "sport-specific" tests. It seems not always easy to separate "cognition" from "sport-specific skill testing", and although open skills specific to the demands of skillful soccer performance (e.g., Foskett et al., 2009), simulated golf performance (Stevenson et al., 2009), vigilance and reaction time in a soccer-specific exercise 
(Coull et al., 2015, 2016), ball-handling scores, passing accuracy, tennis serving, and so on (Williams \& Rollo, 2015) are not "pure cognitive" measurements, they are useful for the sport setting.

\section{Dehydration}

The effect of hydration status on the performance of various exercise tasks has been studied extensively, and hydration status can also affect the brain (Meeusen, 2014). Dehydration and hyperthermia (Watson et al., 2006) result in transient openings of the blood-brain barrier, and this may have implications for the stability of the cerebral environment during exercise. By using magnetic resonance imaging, Kempton et al. (2011) showed that, when dehydrated, subjects exerted a higher level of neuronal activity in order to achieve the same performance level. There is evidence that mild dehydration can impair cognitive performance and mood even without hyperthermia (Ganio et al., 2011), inducing a negative influence on vigilance and working memory and increasing tension, anxiety, and fatigue (Ganio et al., 2011). Almost 20 years ago, McGregor et al. already showed that performance on a soccer skill test was negatively influenced by dehydration compared to a fluid trial (McGregor et al., 1999). Given the limited availability of brain metabolic resources, these findings suggest that prolonged states of reduced water intake may adversely impact executive functions such as planning and visuospatial processing (Kempton et al., 2011). This might have implications in team sports and those sports in which decision making is important.

\section{Creatine}

It is well known that supplementation of creatine monohydrate will increase muscle creatine, resulting in improved performance in short duration, intensive exercise (see Rawson et al., 2018). In the brain, creatine will buffer energy supply as well (Rae \& Broër, 2015), since the brain is an organ with high energy demands (Reinmuth et al., 1965). Emerging evidence suggests that creatine has a positive effect on brain functions (including cognition) in circumstances where brain energy supply is suboptimal (Rae et al., 2003). However, the evidence for a positive effect of creatine on brain function in healthy individuals is only moderate (Rae \& Broër, 2015; see also Rawson et al., 2018).

\section{Nutritional Supplements and Fatigue}

Events arising entirely from within the brain can influence an individual's sensation of fatigue and thus potentially affect performance. This opens an opportunity to manipulate the central nervous system through changes in diet or supplementation with specific nutrients, including amino acids such as branched-chain amino acids (BCAAs), tyrosine, carbohydrates (CHO), and caffeine (Table 1).

The original central fatigue hypothesis (Newsholme et al., 1987) suggested that changes in the mobilization of substrates $(\mathrm{CHO}$, fat) that occurs during exercise produces a direct effect on the production of the neurotransmitter serotonin (5-HT) within the brain. During exercise, the entry of tryptophan-precursor of 5-HT-into the central nervous system through the blood-brainbarrier is favored by increased muscle BCAAs and elevated plasma fatty acids, as this elevates the ratio of unbound tryptophan to BCAA. This increases the amount of tryptophan crossing the bloodbrain-barrier, consequently leading to higher 5-HT concentrations in the brain (Meeusen, 2014; Roelands \& Meeusen, 2010). Serotonin has been linked to fatigue because of its well-known effects on sleep, lethargy, and loss of motivation. An exercise-induced increase in extracellular serotonin concentrations in several brain regions was suggested to contribute to the development of fatigue during prolonged exercise (Newsholme et al., 1987).

\section{Branched Chain Amino Acid and Central Fatigue}

The ingestion of BCAAs causes a rapid elevation of their plasma concentrations and increases their uptake into the brain. Supplementation of BCAAs has been proposed as a possible strategy to limit the development of central fatigue. Although this is a very attractive theory, there is limited or only circumstantial evidence to suggest that exercise performance in humans can be altered by nutritional manipulation with BCAA supplements (Meeusen, 2014). While there is some evidence of BCAA ingestion influencing ratings of perceived exertion (RPE) and mental performance, the results of several well-controlled laboratory studies have failed to demonstrate a clear positive effect on exercise capacity or performance during prolonged fixed-intensity exercise to exhaustion (Van Hall et al., 1995), prolonged time-trial performance, incremental exercise, or intermittent shuttle running (Meeusen \& Watson, 2007; Watson et al., 2004).

\section{Tyrosine and Central Fatigue}

Brain function is not determined by a single neurotransmitter system, and the interaction between brain 5-HT and dopamine (DA) during prolonged exercise has also been explored as having a regulative role in the development of fatigue. This revised central fatigue hypothesis suggests that an increase in central ratio of 5-HT to DA is associated with feelings of tiredness and lethargy, accelerating the onset of fatigue, whereas a low ratio favors improved performance through the maintenance of motivation and arousal (see Meeusen \& Roelands, 2017 for a recent review). In a similar manner to 5-HT, brain DA and noradrenaline (NA) synthesis is reliant on the delivery of the nonessential amino acid tyrosine, but the rate of production appears to be also limited by the activity of the catecholaminergic neurons. Oral doses of tyrosine increase circulating concentrations of adrenaline, NA, and DA both in the central nervous system (CNS) and periphery. These are heavily involved in the regulation of body functions during physical stress and exercise. Tyrosine supplementation appears to prevent declines in various aspects of cognitive performance and mood associated with stress encountered in some military settings (Lieberman, 2003). There is some evidence that vigilance, choice reaction time, pattern recognition, coding, and complex behaviors (such as map-compass reading), are improved by tyrosine administration when volunteers are exposed to the combination of cold and high altitude (Lieberman, 2003). Exercise in the heat represents a specific demand on brain DA which is not apparent in temperate conditions (Watson et al., 2005, 2012). Therefore, the brain tyrosine requirement may be greater with the cumulative demands of exercise and heat stress, and may become a limiting factor for DA synthesis and release. Tumilty et al. (2011) assessed the effects of acute tyrosine supplementation on exercise capacity in the heat, and showed that supplementing a nutritional DA precursor one hour before exercise was associated with increased exercise capacity in the heat. This demonstrated that tyrosine availability, at least in part, may influence prolonged exercise tolerance with heat stress (Roelands et al., 2008). However, the authors could not reproduce 
Table 1 Overview of the Effect of Nutritional Supplements on Cognitive and Exercise Performance

\begin{tabular}{|c|c|c|c|c|c|}
\hline Supplement & Dose & References & $\begin{array}{c}\text { Exercise } \\
\text { Performance }\end{array}$ & Mechanism & $\begin{array}{c}\text { Cognitive } \\
\text { Performance }\end{array}$ \\
\hline \multirow[t]{2}{*}{ BCAA } & 6 or $18 \mathrm{~g}$ & Van Hall et al. (1995) & l & & \\
\hline & $12 \mathrm{~g}$ & Watson et al. (2004) & / (in heat) & & \\
\hline \multirow[t]{5}{*}{ Tyrosine } & $100 \mathrm{mg} / \mathrm{kg}$ & Lieberman (2003) & & & $\begin{array}{c}+ \text { (in cold and at } \\
\text { altitude) }\end{array}$ \\
\hline & $150 \mathrm{mg} / \mathrm{kg}$ & Tumilty et al. (2011) & + (in heat) & & \\
\hline & $150 \mathrm{mg} / \mathrm{kg}$ & Tumilty et al. (2012) & I & & \\
\hline & $2 \times 150 \mathrm{mg} / \mathrm{kg}$ & Coull et al. (2015) & & & $\begin{array}{l}+ \text { (in heat; soccer- } \\
\text { specific test) }\end{array}$ \\
\hline & $\begin{array}{l}2 \times 150 \mathrm{mg} / \mathrm{kg} \text { or } \\
2 \times 75 \mathrm{mg} / \mathrm{kg}\end{array}$ & Coull et al. (2016) & & & / (in heat) \\
\hline \multirow[t]{11}{*}{ Glucose } & Review & Messier (2004) & + & & \\
\hline & Review & $\begin{array}{l}\text { Williams and Rollo } \\
\text { (2015) }\end{array}$ & + (in team sports) & & \\
\hline & Mouth rinse & Sanders et al. (2012) & & & \\
\hline & $\begin{array}{l}\text { Mouth rinse } 6.4 \% \\
\text { maltodextrin }\end{array}$ & Carter et al. (2004) & + & $\downarrow$ perception of effort & \\
\hline & $\begin{array}{l}\text { Mouth rinse } 6.4 \% \\
\text { maltodextrin }\end{array}$ & Chambers et al. (2009) & + & $\begin{array}{l}\uparrow \text { brain activity in reward } \\
\text { centers }\end{array}$ & \\
\hline & $\begin{array}{l}\text { Mouth rinse } 6 \% \\
\text { maltodextrin }\end{array}$ & Rollo et al. (2008) & + & & \\
\hline & $\begin{array}{l}\text { Mouth rinse } 6.4 \% \\
\text { maltodextrin }\end{array}$ & Rollo et al. (2010) & + & & \\
\hline & $\begin{array}{l}\text { Mouth rinse } 6.4 \% \\
\text { maltodextrin }\end{array}$ & Rollo et al. (2011) & + & & \\
\hline & Mouth rinse $6 \%$ glucose & Pottier et al. (2010) & + & & \\
\hline & Mouth rinse $1.6 \mathrm{~g} / 25 \mathrm{ml}$ & De Pauw et al. (2015) & & $\begin{array}{l}\uparrow \text { brain activity in reward } \\
\text { centers }\end{array}$ & l \\
\hline & Nasal spray & $\begin{array}{l}\text { De Pauw, Roelands, } \\
\text { Van Cutsem, Marusic, } \\
\text { et al. (2017) }\end{array}$ & + & & + \\
\hline $\begin{array}{l}\text { Medium-chain } \\
\text { triacylglycerides }\end{array}$ & & & No evidence & & No evidence \\
\hline \multirow[t]{10}{*}{ Caffeine } & $100 \mathrm{mg}$ & Hogervorst et al. (2008) & + & $\downarrow$ perception of effort & + \\
\hline & $6 \mathrm{mg} / \mathrm{kg}$ & Ali et al. (2016) & + & $\begin{array}{l}\downarrow \text { perception of effort, } \\
\uparrow \text { vigor }\end{array}$ & \\
\hline & Review & McLellan et al. (2016) & & & + \\
\hline & Review & Warren et al. (2010) & $\begin{array}{c}\text { (MVC and muscle } \\
\text { endurance })\end{array}$ & & \\
\hline & Meta-analysis & Brown et al. (2013) & / (repeats sprints) & & \\
\hline & Mouth rinse $0.3 \mathrm{~g} / 25 \mathrm{ml}$ & De Pauw et al. (2015) & & $\uparrow$ brain activity & + \\
\hline & Nasal spray & $\begin{array}{l}\text { De Pauw, Roelands, } \\
\text { Van Cutsem, Marusic, } \\
\text { et al. (2017) }\end{array}$ & l & $\uparrow$ brain activity & l \\
\hline & $260 \mathrm{mg}$ & Ferrauti et al. (1997) & $+($ tennis $)$ & $\uparrow$ motor skills & \\
\hline & $6 \mathrm{mg} / \mathrm{kg}$ & Foskett et al. (2009) & $+($ soccer $)$ & $\uparrow$ motor skills & \\
\hline & $6 \mathrm{mg} / \mathrm{kg}$ & Stuart et al. (2005) & + (rugby) & $\downarrow$ perception of effort & \\
\hline Caffeine + glucose & $\begin{array}{l}1.6 \mathrm{mg} / \mathrm{kg} \text { caffeine } \\
+0.64 \mathrm{~g} / \mathrm{kg} \text { carbohydrate }\end{array}$ & Stevenson et al. (2009) & + (golf) & $\uparrow$ alertness & \\
\hline $\begin{array}{l}\text { Caffeine }+ \text { taurine }+ \\
\text { glucose }\end{array}$ & $\begin{array}{l}200 \mathrm{mg} \text { caffeine } \\
+/-2,000 \mathrm{mg} \\
\text { Taurine }+/-50 \mathrm{~g} \text { glucose }\end{array}$ & Giles et al. (2012) & & Caffeine is responsible & + \\
\hline Omega-3 fatty acids & & & No evidence & & No evidence \\
\hline
\end{tabular}


Table 1 (continued)

\begin{tabular}{|c|c|c|c|c|c|}
\hline Supplement & Dose & References & $\begin{array}{c}\text { Exercise } \\
\text { Performance }\end{array}$ & Mechanism & $\begin{array}{l}\text { Cognitive } \\
\text { Performance }\end{array}$ \\
\hline \multirow[t]{2}{*}{ Polyphenols } & $>7$ days (meta-analysis) & Somerville et al. (2017) & + & & \\
\hline & Review & Vauzour (2012) & & $\begin{array}{l}\uparrow \text { regional perfusion; } \\
\downarrow \text { oxidative stress }\end{array}$ & + \\
\hline Quercetin & $\begin{array}{l}>7 \text { days } 764 \mathrm{mg} / \text { day } \\
\text { (meta-analysis) }\end{array}$ & Somerville et al. (2017) & + & & \\
\hline \multirow[t]{3}{*}{ Cocoa flavanol } & 520 or $994 \mathrm{mg}$ & Scholey et al. (2008) & & & + \\
\hline & $450 \mathrm{mg}$ & Francis et al. (2006) & & $\uparrow$ regional perfusion & + \\
\hline & $903 \mathrm{mg}$ & Decroix et al. (2016) & & $\uparrow$ regional perfusion & l \\
\hline \multirow[t]{3}{*}{ Beetroot juice } & Meta-analysis & $\begin{array}{l}\text { Dominguez et al. } \\
\text { (2017) }\end{array}$ & + & & \\
\hline & $\begin{array}{l}12.8 \mathrm{mmol} \text { nitrate/day } \\
7 \text { days }\end{array}$ & Thompson et al. (2015) & + & & + \\
\hline & $5.5 \mathrm{mmol}$ nitrate & Wightman et al. (2015) & & $\uparrow$ regional perfusion & + \\
\hline \multirow[t]{3}{*}{ Ginseng } & Review & Gorby et al. (2010) & & & $\leftrightarrow$ \\
\hline & Meta-analysis & Geng et al. (2010) & & & $\begin{array}{l}\text { potential }+ \text {, but } \\
\text { lack of evidence }\end{array}$ \\
\hline & Meta-analysis & Smith et al. (2014) & & & $\begin{array}{l}\text { potential }+ \text {, but } \\
\text { lack of evidence }\end{array}$ \\
\hline \multirow[t]{3}{*}{ Ginkgo biloba } & Meta-analysis & Laws et al. (2012) & & & I \\
\hline & Review & Gorby et al. (2010) & & & + \\
\hline & $\begin{array}{l}240 \mathrm{mg} / \text { day } 22-26 \text { weeks } \\
\text { (meta-analysis) }\end{array}$ & Tan et al. (2015) & & & $\downarrow$ cognitive decline \\
\hline \multirow[t]{2}{*}{ L-theanine } & Meta-analysis & $\begin{array}{l}\text { Einöther and Martens } \\
\text { (2013) }\end{array}$ & & & + \\
\hline & Review & Bryan (2008) & & & $\begin{array}{c}+ \text { only in combination } \\
\text { with caffeine }\end{array}$ \\
\hline \multirow[t]{3}{*}{ Guarana } & $75 \mathrm{mg}$ & Kennedy et al. (2004) & & & + \\
\hline & $75 \mathrm{mg}$ & Haskell et al. (2007) & & & + \\
\hline & $222 \mathrm{mg}$ & Veasey et al. (2015) & + & $\downarrow$ perception of effort & + \\
\hline \multirow[t]{2}{*}{ Rhodiola rosea } & $3 \mathrm{mg} / \mathrm{kg}$ & Noreen et al. (2013) & + & $\downarrow$ perception of effort & l \\
\hline & $200 \mathrm{mg}$ & De Bock et al. (2004) & + & & \\
\hline \multirow[t]{3}{*}{ Sage } & $600 \mathrm{mg}$ dried & Kennedy et al. (2006) & & & + \\
\hline & $50 \mu \mathrm{l}$ & Tildesley et al. (2003) & & & + \\
\hline & $50 \mu \mathrm{l}$ & Tildesley et al. (2005) & & & + \\
\hline
\end{tabular}

Abbreviations: $/=$ no effect; $+=$ positive effect; $\downarrow=$ decrease; $\uparrow=$ increase; MVC $=$ maximal voluntary contraction.

the results when a simulated time trial was used as the performance measure (Tumilty et al., 2012). Similar contrasting results were found in two studies using tyrosine supplementation (Coull et al., $2015,2016)$. In a first study, they showed that tyrosine supplementation was associated with improved vigilance and reaction time when exposed to individualized soccer-specific exercise in a warm environment. This suggested that increasing the availability of tyrosine may improve cognitive function during exposure to exercise-heat stress. In a follow-up work, the same group found that exercise in heat stress impaired some aspects of cognitive function, but tyrosine did not alleviate these decrements. The results of the above mentioned studies illustrate the importance of checking the exact composition of the nutritional supplement used. Tyrosine used by Coull et al. (2015) was obtained from an online sport nutrition company, while in their second study they used a medical supplement (i.e., a pure tyrosine supplement). This is important to consider due to the known uncertainty regarding the composition of widely-available nutritional supplements in the field (Maughan,
2005, Watson et al., 2012). The implications for the sports performance thus remain unclear, but despite a good rationale for its use, evidence of an ergogenic benefit of tyrosine supplementation during prolonged exercise is limited (Meeusen \& Watson, 2007).

\section{Carbohydrates and Central Fatigue}

Another nutritional strategy that may influence the development of central fatigue is carbohydrate feeding. The beneficial effect of carbohydrate supplementation during prolonged exercise could also relate to increased (or maintained) substrate delivery for the brain, with a number of studies indicating that hypoglycemia affects brain function and cognitive performance (Meeusen, 2014).

The brain consumes ca. $130 \mathrm{~g}$ of glucose daily (Reinmuth et al., 1965); thus, in a resting state, a large portion of the available glucose will be used by the brain. Glucose is stored in the brain as glycogen in the astrocytes (Wender et al., 2000) and can be degraded in response to sudden increases in energy demand 
such as periods of increased neuronal activity (Brown \& Ransom, 2007), during cognitive processes, and in prolonged endurance exercise (Matsui et al., 2011). Glucose and glycogen are the primary fuel source of the brain, but lactate also can contribute to fueling the brain. Especially during periods of high brain activation, astrocytes metabolize glucose, forming lactate as a by-product (Dienel, 2012) which will serve as additional fuel (Dienel, 2012). Glucose appears to have a greater effect on cognition when task difficulty is increased or when attention is divided between two tasks (Messier, 2004). There is also evidence that impaired glucose regulation is associated with impaired cognition, particularly episodic memory. This impairment is minimal in young people but increases in older people where it may compound other aging processes, leading to reduced brain function (Messier, 2004). Hypoglycemia during exercise could be related to a reduced delivery of glucose as a substrate to the brain, and carbohydrate feedings are associated with enhanced perceived activation and a lowered perception of effort during intermittent running in comparison to the ingestion of placebo (Williams \& Rollo, 2015).

The role of carbohydrate and a possible direct link with the brain was shown by several mouth-rinse studies. Simply the presence of a glucose solution in the mouth can result in improved physical (Chambers et al., 2009) and cognitive performance (Sanders et al., 2012). Carter et al. (2004) reported a 3\% increase in performance following the rinsing of a maltodextrin solution around in the mouth before and during exercise. No solution was actually ingested during the protocol, suggesting that this performance benefit may have been mediated through direct communication between receptors present in the mouth and the brain. Since then, several other groups have also examined the effects of a carbohydrate mouth rinse on performance (Pottier et al., 2010, Rollo et al., 2008, 2010, 2011). Interestingly, most studies that found a positive effect were carried out in the fasted state. When a carbohydrate mouth rinse was performed in a fed state, no effect on performance in 45-min (Whitham et al., 2007) and 60-min time trials were observed (Beelen et al., 2009). The authors suggested that the oral perception of carbohydrate perhaps only plays a role when muscle and liver glycogen stores are reduced. However, this finding was not replicated in a study by Fares and Kayser (2011). The concept of the carbohydrate mouth rinse has been supported by work investigating brain activity following the ingestion of a bolus of glucose (Liu et al., 2000), and research demonstrating the activation of several brain regions after rinsing carbohydrate solutions within the mouth (Chambers et al., 2009). Those studies highlight a marked increase in brain activation, occurring immediately after carbohydrate enters the mouth, with a second spike in activity observed 10 min following ingestion, presumably occurring as the substrate enters the circulation. The presence of glucose in the oral cavity increases activity in the anterior cingulate cortex, the ventral striatum (Chambers et al., 2009), as well as the orbitofrontal cortex (De Pauw et al., 2015). The activation of these reward centers of the brain has been suggested to induce an ergogenic effect on exercise performance by reducing RPE during exercise (Carter et al., 2004). Despite the convincing evidence on glucose mouth rinse and its effects on exercise performance, there is evidence that any benefit of $\mathrm{CHO}$ mouth rinse is lost when exercise is performed in a warm environment (e.g., Cramer et al., 2015; Watson et al., 2014).

Recently, a glucose nasal spray clearly showed the direct connection between the nasal mucosa and several brain areas. Glucose nasal spray substantially increased the average power output during a time trial. In line with mouth rinsing, glucose showed to substantially enhance endurance performance, probably due to the activation of the olfactory pathway and/or extraoral sweet taste receptors. Greater cognitive efficiency was observed with glucose nasal spray (De Pauw, Roelands, Van Cutsem, Decroix, et al., 2017; De Pauw, Roelands, Van Cutsem, Marusic, et al., 2017).

\section{Other Brain Fuels}

Ketone bodies such as acetoacetate and $\beta$-hydroxybutyrate $(\beta \mathrm{HB})$ are synthesized in the liver from fatty acids when carbohydrate levels are low. Ketones act as a back-up fuel for the brain when energy levels are low, such as during periods of starvation (Holdsworth et al., 2017; Owen et al., 1967). It is therefore hypothesized that dietary supplementation with medium-chain triacylglycerides (TAG) can improve cognitive function by providing the brain with energy in the form of ketones (Holdsworth et al., 2017; Volek et al., 2015). Recently, several animal studies explored the possibility of the therapeutic potential of cerebral ketone metabolism in CNS pathologies such as Alzheimer disease (AD), Parkinson's disease, and others. However, only a few human studies examined the influence of nutritional ketosis on cognitive outcomes in mild to moderate $\mathrm{AD}$ and in mild cognitive impairment. While this effect may be attributable in part to correction of hyperinsulinemia, other mechanisms associated with ketosis, such as reduced inflammation and enhanced energy metabolism, also may have contributed to improved neurocognitive function (Krikorian et al., 2012). Much more research is warranted to evaluate the possible preventive potential and mechanisms of action of ketones in the context of early neurodegeneration. Therefore, although some animal studies and data from studies with elderly and persons with degenerative neurological disorders seem to indicate that very low carbohydrate consumption, even in the short-term, can improve memory function in older adults with increased risk for Alzheimer's disease (Krikorian et al., 2012), anecdotal expressions such as "ultra-endurance athletes frequently report that mental clarity is maintained better during prolonged exercise in the keto-adapted state" (Volek et al., 2015, p. 4) cannot be sufficient to provide evidence for the use of ketones, ketone ester drinks, or keto-adapted diets as possible nutritional interventions to influence mental performance of athletes.

\section{Caffeine and Central Fatigue}

Caffeine has long been recognized as an ergogenic aid. For a while, caffeine use was restricted for athletes and it was only removed from the list of controlled substances in January 2004, when it was put on the monitoring list. The stimulatory effect of caffeine is believed to stem from its ability to antagonize the actions of adenosine (Dunwiddie \& Masino, 2001). Caffeine is very similar in structure to adenosine and can bind to cell membrane receptors for adenosine, thus blocking their action (Graham, 2001). Caffeine easily crosses the blood-brain barrier due to its lipophilic properties (McCall et al., 1982) and has been shown to counteract most of the inhibitory effects of adenosine on neuroexcitability (Fredholm et al., 1999), neurotransmitter release (Okada et al., 1997), and arousal (Porkka-Heiskanen, 1999). Since caffeine is known to antagonize adenosine receptors in the brain, and adenosine inhibits the release of DA, logically, caffeine will induce higher brain DA concentrations (Davis et al., 2003). Low to moderate $\left(0.5 \mathrm{mg} \cdot \mathrm{kg}^{-1}\right.$ to $4 \mathrm{mg} \cdot \mathrm{kg}^{-1}$ ) caffeine doses improve alertness, vigilance, attention, and reaction time, but less consistent effects are observed on memory and higher-order executive function, such as judgment 
and decision making (Mclellan et al., 2016). Caffeine is well known to enhance performance and reduce perception of effort during prolonged exercise (Hogervorst et al., 2008) and will also influence these specific reward centers of the brain. A caffeine mouth rinse has also improved reaction time during an incongruent Stroop task (De Pauw et al., 2015). Both the orbitofrontal and dorsolateral prefrontal cortex were activated only during a caffeine mouth rinse, potentially explaining the likely beneficial effect on reaction times. A caffeine nasal spray activated cingulate, insular, and sensorimotor cortices (De Pauw, Roelands, Van Cutsem, Decroix et al., 2017; De Pauw, Roelands, Van Cutsem, Marusic et al., 2017).

Human studies using a variety of protocols have shown performance improvements after caffeine intake (Roelands \& Meeusen, 2010). Many studies have shown that caffeine is ergogenic for prolonged endurance exercise performance (Maughan et al., 2018; Peeling et al., 2018; Rawson et al., 2018), but literature is not that consistent on the effects of caffeine on single-sprint, multiple-sprint, or team sport. A low dose (up to $6 \mathrm{mg} \cdot \mathrm{kg}^{-1}$ ) is likely to improve intermittent, but not repeated, sprint performance (Bishop, 2010). Furthermore, there is no apparent increase in the rate of fatigue development attributable to initial improvements in work and power achieved during intermittent-sprint tests as a consequence of caffeine ingestion (Bishop, 2010). Ali et al. (2016) examined the influence of caffeine supplementation on cognitive performance and perceptual responses in female teamgame players. They found that caffeine supplementation showed a positive effect on perceptual parameters by increasing vigor and a tendency to decrease fatigue during intermittent running activity in female games players. Stevenson et al. (2009) examined the effect of a carbohydrate-caffeine sports drink on simulated golf performance and found that putting performance and self-rated scores for alertness and relaxation were positively influenced by the sports drink. It seems that the consumption of an isotonic carbohydrate sports drink containing caffeine prior to and during a round of golf improved putting performance and increased feelings of alertness (Stevenson et al., 2009). Energy drinks containing caffeine, taurine, and glucose may improve mood and cognitive performance. Giles et al. (2012) assessed the individual and interactive effects of these ingredients on cognitive performance and mood in 24-hr caffeineabstained habitual caffeine consumers, using a randomized, double-blind, mixed design. Caffeine enhanced executive control and working memory, and reduced simple and choice reaction time. Taurine increased choice reaction time, but reduced reaction time in the working memory tasks. Glucose alone slowed choice reaction time. Glucose, in combination with caffeine, enhanced object working memory and, in combination with taurine, enhanced orienting attention. Limited glucose effects may reflect low-task difficulty relative to subjects' cognitive ability. Caffeine reduced feelings of fatigue and increased tension and vigor. Taurine reversed the effects of caffeine on vigor and caffeine-withdrawal symptoms. No effects were found for salivary cortisol or heart rate. Caffeine, but not taurine or glucose, is likely responsible for reported changes in cognitive performance following consumption of energy drinks, especially in caffeine-withdrawn habitual caffeine consumers (Giles et al., 2012).

A meta-analysis on the effect of caffeine ingestion on maximal voluntary contraction (MVC) concluded that, overall, caffeine improves MVC strength and muscular endurance (Warren et al., 2010). Several studies examined the effect of caffeine on sportsspecific situations (e.g., Brown et al., 2013; Ferrauti et al., 1997; Foskett et al., 2009; Stuart et al., 2005). The skills examined varied from ball-handling scores, passing accuracy, tennis serving, etc.
Most of the studies showed that low doses of $3-6 \mathrm{mg} \cdot \mathrm{kg}^{-1}$ of caffeine can improve cognitive performance, motor skills, and endurance exercise. Besides ergogenic effects, caffeine also increases resting energy expenditure, mental energy, and neuromuscular coordination, elevates mood, and relieves anxiety (Glade, 2010). Caffeine may thus reduce perception of effort and pain during exercise, thereby allowing subjects to perform at higher workloads for a longer period of time. Caffeine has been shown to be effective in relatively low doses $\left(3 \mathrm{mg} \cdot \mathrm{kg}^{-1}\right)$ and its effect seems to level off at $6 \mathrm{mg} \cdot \mathrm{kg}^{-1}$, and therefore very high doses should not be recommended. Given the widespread use of caffeine, the level of habitual intake may be an important factor to consider when undertaking caffeine supplementation with the view to enhancing performance. It seems that regular users may display an altered sensitivity to its effects. There is some mixed evidence whether habitual caffeine intake influences the performance benefits (Gonçalves et al., 2017), but chronic ingestion of a low dose of caffeine has recently been shown to induce tolerance to the performance benefits of caffeine in nonusers (Beaumont et al., 2017). In some caffeine-naive individuals, caffeine can produce several side effects, such as tachycardia and palpitations, nervousness, dizziness, and gastrointestinal symptoms that may be detrimental to performance. These side effects can be minimized by using low doses of caffeine (e.g., $3 \mathrm{mg} \cdot \mathrm{kg}^{-1}$ body mass) as is currently recommended, while still conferring performance benefits. The positive (and possible negative) effects of caffeine seem very individually determined, so previous experience with doses and timing is essential before using supplementation in competitive environments.

\section{Supplements, Plant Products, and Herbal Extracts}

\section{Omega-3 Fatty Acids}

Omega-3 fatty acids are essential for supporting intercellular signaling events, and therefore positively influence synaptic function. Many clinical and animal studies demonstrate the importance of long-chain polyunsaturated fatty acids (LCPUFA) in neural development and neurodegeneration. Omega-3 fatty acids such as docosahexaenoic acid (DHA) are involved in multiple brain functions including cell membrane fluidity, receptor affinity, modulation of signal transduction molecules, and cognitive function (Barrett et al., 2014). Recently, these fatty acids are suggested to act as recovery aids, or possibly as a prophylactic nutritional measure for concussion or mild traumatic brain injury. Animal studies and (pre)clinical studies show that DHA might have a positive effect on the outcomes of mild traumatic brain injury. However, there is a need for well-controlled studies before LCPUFA supplementation can be advised as a therapeutic or preventative measure against sports-related concussion (Barrett et al., 2014).

\section{Plant Products}

Naturally-occurring plant products and herbal extracts such as polyphenols, ginseng, ginkgo biloba, and others have grown in popularity as possible agents to improve performance or recovery from exercise. These dietary constituents are marketed as supplements to enhance (sports) performance. Biological supplements typically contain chemical compounds extracted from fruits, vegetables, roots, and others. Some of these supplements seem to have an influence on the CNS, while others will not influence the 
brain. Many are thought to enhance cognitive function and postpone (central) fatigue, but there is little evidence that they influence sports performance. Most of the literature on the possible positive effects of plant products and herbal products on the brain comes from animal studies or studies on subjects with cognitive decline. In several of these studies, positive effects of these products were shown, however the literature on the effects of these products on sports performance is scarce. The existing literature should also be examined carefully because most lack sufficient statistical power, or do not use standardized or pure extracts. Also, many studies have a weak design (e.g., not double-blind and placebo-controlled), and there is a wide variety of cognitive or skill tests used. Furthermore, in many studies looking at herbal extracts, the authors rarely confirm the composition of the supplement (e.g., Does it contain what is says it does and does it contain other ingredients not listed on the label, such as caffeine?). Also the bioavailability of many of these substances is often very low, particularly the polyphenol compounds. Taken together, it is not surprising that studies produce inconsistent results. This should be highlighted.

\section{Polyphenols}

There has recently been growing interest, supported by a number of epidemiological and experimental studies, on the possible beneficial effects of polyphenols on brain health (Shukitt-Hale et al., 2008; Vazour, 2012). Polyphenols are abundant micronutrients in plantderived foods and are powerful antioxidants. Fruits and beverages such as tea, red wine, cocoa, and coffee are major dietary sources of polyphenols. The largest group of polyphenols is the flavonoids. There are six dietary groups of flavonoids: flavones (e.g., apigenin, luteolin), which are found in parsley and celery; flavanones/flavanonols (e.g., hesperetin, naringenin/astilbin, engeletin), which are mainly found in citrus fruit, herbs (oregano), and wine; isoflavones (e.g., daidzein, genistein), which are mainly found in soy and soy products; flavonols (e.g., kaempferol, quercetin), which are found in onions, leeks, and broccoli; flavanols (e.g., -catechin, [-]-epicatechin, epigallocatechin, and epigallocatechin gallate), which are abundant in green tea, red wine, and chocolate; and anthocyanidins (e.g., pelargonidin, cyanidin, and malvidin), whose sources include red wine and berry fruits. The nonflavonoid group of polyphenols may be separated into two different classes: the phenolic acids, including the hydroxybenzoic acids (C1-C3 skeleton) and hydroxycinnamic acids (C3-C6 skeleton), and the stilbenes (C6-C2-C6 skeleton). Caffeic acid is generally the most abundant phenolic acid, and is mainly found as the quinic ester, chlorogenic acid in blueberries, kiwis, plums, and apples. Resveratrol, the main stilbene, can be found in the cis or trans configurations, either glucosylated (piceid) or in lower concentrations as the parent molecule of a family of polymers such as viniferins, pallidol, or ampelopsin A. Resveratrol dietary sources include grapes, wine, and peanuts.

Polyphenol intake can be increased by conscious dietary choices of foods with high content (juices, tea infusions, chocolate, etc.), but the concentration of active substances are much higher in supplements. Some of the experiments performed in animal studies typically used high doses, which represent sometimes large amounts of fresh fruits to have the same absolute amount of active substances in humans.

A recent first meta-analysis of polyphenols and their effect on human athletic performance suggest that polyphenol supplementation (and especially quercetin) is associated with a clear moderate improvement of performance with no reported adverse effects (Somerville et al., 2017). Polyphenols have consistently been associated with a reduced risk of developing dementia, improved cognitive performance in normal aging, and improved cognitive evolution (Vazour, 2012). The neuroprotective actions of dietary polyphenols involve a number of effects within the brain, including a potential to protect neurons against injury induced by neurotoxins, an ability to suppress neuroinflammation, and the potential to promote memory, learning, and cognitive function (Meeusen, 2014; Vazour, 2012). While many of the mechanisms underpinning their beneficial effects remain to be elucidated, it has become clear that they partly involve decreases in oxidative/inflammatory stress signaling, increases in protective signaling, and may also involve hormetic effects to protect neurons against oxidative and inflammatory stressors. Also, polyphenols can improve regional cerebral perfusion (Decroix et al., 2016; Lamport et al., 2015).

Flavonoids. The emerging evidence suggests that flavonoids may be beneficial to attention, working memory, and psychomotor processing speed in a general population. Episodic memory effects are less well defined and may be restricted to child or older adult populations. The evidence also points toward a dose-dependent effect of flavonoids, but the physiological mechanisms of action remain unclear. Overall, there is encouraging evidence that flavonoid supplementation can benefit cognitive outcomes within an acute time frame of $0-6 \mathrm{hr}$, especially in the elderly population. But, larger studies, combining cognitive and physiological measures, are needed to strengthen the evidence base.

Cocoa flavanols. Cocoa flavanols, as found in dark chocolate, have been reported to have beneficial effects on cognition (Francis et al., 2006; Scholey et al., 2008) but it is not known if this effect is also present in combination with exercise. Acute cocoa flavanols intake increased cerebral oxygenation during a cognitive task assessing executive function, but without any impact on cognitive performance. When combining cocoa flavanols and exercise, cocoa flavanols had no additive effect on the exercise-induced cognitive enhancement and the associated increased cerebral oxygenation and perfusion (Decroix et al., 2016). The increased cerebral perfusion caused by acute cocoa flavanol intake is supported by a nitric oxide mediated vasodilatation (Nehlig, 2013). Also, due to the large variation in flavanol content in chocolate and cocoa products, it is critical to compare the dosages of flavanols rather than simply the amounts of chocolate or administered cocoa products in clinical trials (Ried et al., 2012).

Beetroot juice. Beetroot juice is used as a supplement because of its high inorganic nitrate $\left(\mathrm{NO}^{-}\right)$content, a compound found naturally in vegetables. Nitrate derived from vegetables is consumed as part of a normal diet and is reduced endogenously via nitrite to nitric oxide. Most studies suggest that supplementation with beetroot juice can improve cardiorespiratory endurance in athletes by increasing efficiency, which improves performance at various distances, increases time to exhaustion at submaximal intensities, and may improve the cardiorespiratory performance at anaerobic threshold intensities and maximum oxygen uptake (Domínguez et al., 2017). Dietary nitrate has been shown to improve endothelial function, reduce blood pressure and the oxygen cost of submaximal exercise, and increase regional perfusion in the brain. The results of two recent studies show that single doses of dietary nitrate enhances repeated sprint performance and may attenuate the decline in cognitive function (and, specifically, reaction time) that may occur during prolonged intermittent exercise (Thompson et al., 2015). It modulates the cerebral blood flow response to task performance and potentially improves cognitive performance (Wightman et al., 2015). 
Other plant products. The consumption of tea, polyphenol-rich foods, fruit and vegetables, and total amounts of flavonoids have been shown to be associated with protection against, or slowed progression of, cerebrovascular diseases, such as stroke and neurologic disorders, including dementia, and cognitive impairment/ decline in elderly populations. The literature on the effects of the above supplements and plant products on a healthy young population however is very scarce. Especially, literature on the effects of these products on brain functioning, cognition, motor performance, and so on, in an athlete population is almost inexistent.

Ginseng is commonly used in individuals who are fatigued and under stress, but most studies on cognitive aspects (alertness, fatigue, mood, motivation) show mixed results (Gorby et al., 2010). In a study on biathlon athletes, Dalinger (1966) found that ginseng improved ratings of fatigue and motor skills (target hits in the shooting event). Exercise-induced mental/physical stress and fatigue is an important factor involved in sports performance, but there is currently not enough evidence to support a cognitionenhancing effect of ginseng (Geng et al., 2010; Smith et al., 2014).

Ginkgo biloba is a herbal extract widely used in traditional Chinese medicine. Ginkgo biloba is believed to improve memory and other aspects of cognitive function. The results on the acute effects of Ginkgo biloba intake are conflicting (Gorby et al., 2010). Two recent meta-analyses show different results. Laws et al. (2012) did not find positive effects, while Tan et al. (2015) concluded that a ginkgo biloba extract was able to stabilize or slow down the decline in cognition. As far as we know, there are no studies of ginkgo biloba on athletes.

One nonprotein amino acid that is an important constituent of tea is L-theanine. The tea ingredients caffeine and theanine, alone or in combination, have been linked to attention, with the available research showing that consumption of black tea improves attention on validated complex tasks as well as self-reported alertness (Einöther \& Martens, 2013). However, the effect of theanine alone does not show the same results (Bryan, 2008).

Guarana seed comes from plants found in the Amazon, and it contains theophylline, theobromine, and caffeine. Theobromine is a methylxanthine that is an adenosine receptor antagonist (as caffeine) and might improve cognitive function. Two studies (Haskell et al., 2007; Kennedy et al., 2004) have investigated the effects of guarana on cognitive performance and found that memory, mood, and speed during an attention task improved. The administration of a vitamin and mineral complex with guarana has been shown to attenuate mental fatigue and improve performance during cognitively-demanding tasks (Haskell et al., 2007; Kennedy et al., 2004). Veasey et al. (2015) showed that consuming a vitamin and mineral complex containing guarana, prior to exercise, can positively impact subsequent memory performance and reduce perceived exertion during a moderate-intensity run in active males. Probably, the caffeine content and/or the combination with theobromine could be responsible for these effects. Pomportes et al. (2017) recently investigated the influence of serial mouth rinsing with guarana complex on cognitive performance (i.e., cognitive control and time perception) during a 40-min submaximal exercise, and found a likely improvement on a cognitive task. However, when examined more carefully, this commercial product also contains caffeine. Again, this emphasizes that we should interpret the literature carefully before drawing conclusions on possible beneficial effects on exercise performance and cognition.

Other plant products such as Rhodiola rosea and sage might also improve cognitive performance and reaction time. Rhodiola rosea is reported to influence endurance performance (De Bock et al., 2004), but in this study there was no specific influence on sustained attention or reaction time. Noreen et al. (2013) examined the effect of an acute dose of Rhodiola rosea on endurance exercise performance, perceived exertion, mood, and cognitive function. They found that ingestion of $3 \mathrm{mg} \cdot \mathrm{kg}^{-1}$ Rhodiola rosea decreases heart rate response to submaximal exercise and appears to improve endurance exercise performance by decreasing the perception of effort. No effects on cognition were found. Sage improves alertness (Kennedy et al., 2006) and memory (Tildesley et al., 2003, 2005). No studies with sage were performed in athletes.

\section{Conclusion}

The brain uses a large amount of energy and it seems that it is not that easy to disturb brain homeostasis. Several nutrients and supplements will influence brain functioning, but not many of these nutritional constituents have been the subject of well-controlled studies in exercise science. Carbohydrate and caffeine have an influence on several aspects of cognitive function, and they can also influence exercise performance. For most of the herbal products, there is only "anecdotal" evidence that they can influence brain functions. However, more studies are necessary to determine the exact dosage of supplementation, and also which cognitive domains are influenced the most when these supplements are taken. Most of the other supplements that have evidence to influence brain function in specific populations, such as individuals with cognitive decline, dementia, or Alzheimer's disease, lack evidence in sports science. There is a need for well-controlled randomized studies with welldefined outcome measures before the "claims" on beneficial effects of supplements on brain functioning can be established.

\section{Acknowledgments}

Manuscript writing was done by RM. LD assisted in manuscript writing and revision. RM and LD declare no conflicts of interest.

\section{References}

Ali, A., O’Donnell, J., Von Hurst, P., Foskett, A., Holland, S., Starck, C., \& Rutherfurd-Markwick, K. (2016). Caffeine ingestion enhances perceptual responses during intermittent exercise in female teamgame players. Journal of Sports Sciences, 34(4), 330-341. PubMed doi:10.1080/02640414.2015.1052746

Barrett, E., McBurney, M., \& Ciappio, E. (2014). Omega-3 fatty acid supplementation as a potential therapeutic aid for the recovery from mild traumatic brain injury/concussion. Advanced Nutrition, 5(3), 268-277. doi:10.3945/an.113.005280

Beaumont, R., Cordery, P., Funnell, M., Mears, S., James, L., \& Watson, P. (2017). Chronic ingestion of a low dose of caffeine induces tolerance to the performance benefits of caffeine. Journal of Sports Sciences, 35(19), 1920-1927. PubMed doi:10.1080/02640414.2016.1241421

Beelen, M., Berghuis, J., Bonaparte, B., Ballak, S.B., Jeukendrup, A.E., \& van Loon, L.J. (2009). Carbohydrate mouth rinsing in the fed state: Lack of enhancement of time-trial performance. International Journal of Sport Nutrition and Exercise Metabolism, 19(4), 400-409. PubMed doi:10.1123/ijsnem.19.4.400

Berthoud, H. (2007). Interactions between the "cognitive" and "metabolic" brain in the control of food intake. Physiology \& Behavior, 91, 486-498. PubMed doi:10.1016/j.physbeh.2006.12.016

Bishop, D. (2010). Dietary supplements and team-sport performance. Sports Medicine, 40(12), 995-1017. doi:10.2165/11536870-000000000-00000 
Brown, A.M., \& Ransom, R. (2007). Astrocyte glycogen and brain energy metabolism. Glia, 55(12), 1263-1271. PubMed doi:10.1002/glia.20557

Brown, S.J., Brown, J., \& Foskett, A. (2013). The effects of caffeine on repeated sprint performance in team sport athletes-a meta-analysis. Exercise and Sport Science Reviews, 22, 25-32.

Bryan, J. (2008). Psychological effects of dietary components of tea: Caffeine and L-theanine. Nutrition Reviews, 66(2), 82-90. PubMed doi:10.1111/j.1753-4887.2007.00011.x

Carter, J.M., Jeukendrup, A.E., \& Jones, D.A. (2004). The effect of carbohydrate mouth rinse on 1-h cycle time trial performance. Medicine \& Science in Sports \& Exercise, 36(12), 2107-2111. PubMed doi:10.1249/01.MSS.0000147585.65709.6F

Chambers, E.S., Bridge, M.W., \& Jones, D.A. (2009). Carbohydrate sensing in the human mouth: Effects on exercise performance and brain activity. Journal of Physiology, 587(8), 1779-1794. doi:10. 1113/jphysiol.2008.164285

Coull, N., Chrismas, B., Watson, P., Horsfall, R., \& Taylor, L. (2016). Tyrosine ingestion and its effects on cognitive and physical performance in the heat. Medicine \& Science in Sports \& Exercise, 48(2), 277-286. PubMed doi:10.1249/MSS.0000000000000757

Coull, N., Watkins, S., Aldous, J., Warren, L., Chrismas, B., Dascombe, B., ... Taylor, L. (2015). Effect of tyrosine ingestion on cognitive and physical performance utilising an intermittent soccer performance test (iSPT) in a warm environment. European Journal of Applied Physiology, 115(2), 373-386. PubMed doi:10.1007/s00421-014-3022-7

Cramer, M., Thompson, M.W., \& Periard, J.D. (2015). Thermal and cardiovascular strain mitigate the potential benefit of carbohydrate mouth rinse during self-paced exercise in the heat. Frontiers in Physiology, 6, 354.

Dalinger, O. (1966). Effect of eleutherococcus extract on functional state of cardiovascular system and working capacity of skiers. In: A.S. Saratikov (Ed.), Stimulants of the central nervous system (pp. 106-111). Tomsk, Russia: Tomsk University Publishing Press.

Davis, J.M., Zhao, Z., Stock, H.S., Mehl, K.A., Buggy, J., \& Hand, G.A. (2003). Central nervous system effects of caffeine and adenosine on fatigue. American Journal of Physiology, 284, R399-R404. PubMed

De Bock, K, Eijnde, B.O., Ramaekers, M., \& Hespel, P. (2004). Acute Rhodiola rosea intake can improve endurance exercise performance. International Journal of Sport Nutritioan and Exercise Metabolism, 14, 298-307. doi:10.1123/ijsnem.14.3.298

De Pauw, K., Roelands, B., Knaepen, K., Polfliet, M., Stiens, J., \& Meeusen, R. (2015). Effects of caffeine and maltodextrin mouth rinsing on P300, brain imaging, and cognitive performance. Journal of Applied Physiology, 118(6), 776-782. PubMed doi:10.1152/ japplphysiol.01050.2014

De Pauw, K., Roelands, B., Van Cutsem, J., Decroix, L., Valente, A., Taehee, K., ... Meeusen, R. (2017). Do glucose and caffeine nasal sprays influence exercise and/or cognitive performance? International Journal of Sports Physiology and Performance, 1, 1-22.

De Pauw, K., Roelands, B., Van Cutsem, J., Marusic, U., Torbeyns, T., \& Meeusen, R. (2017). Electro-physiological changes in the brain induced by caffeine or glucose nasal spray. Psychopharmacology, 234(1), 53-62. doi:10.1007/s00213-016-4435-2

Decroix, L., Tonoli, C., Soares, D., Tagougui, S., Heyman, E., \& Meeusen, R. (2016). Acute cocoa flavanol improves cerebral oxygenation without enhancing executive function at rest or after exercise. Journal of Applied Physiology, Nutrition and Metabolism, 41(12), 12251232. doi:10.1139/apnm-2016-0245

Dienel, G. (2012). Brain lactate metabolism: The discoveries and the controversies. Journal of Cerebral Blood Flow \& Metabolism, 32, 1107-1138. doi:10.1038/jcbfm.2011.175
Domínguez, R., Cuenca, E., Maté-Muñoz, J., García-Fernández, P., SerraPaya, N., Estevan, M., .. . Garnacho-Castaño, M. (2017). Effects of beetroot juice supplementation on cardiorespiratory endurance in athletes. A systematic review. Nutrients, 9(1), 43. doi:10.3390/nu9010043

Dunwiddie, T.V., \& Masino, S.A. (2001). The role and regulation of adenosine in the central nervous system. Annual Reviews Neuroscience, 24(1), 31-55. doi:10.1146/annurev.neuro.24.1.31

Einöther, S.J., \& Martens, V.E. (2013). Acute effects of tea consumption on attention and mood. American Journal of Clinical Nutritrion, 98(6 Suppl.), 1700S-1708S. doi:10.3945/ajcn.113.058248

Fares, E.J., \& Kayser, B. (2011). Carbohydrate mouth rinse effects on exercise capacity in pre- and postprandial states. Journal of Nutrition and Metabolism, 2011, 1-6. PubMed doi:10.1155/2011/385962

Ferrauti, A., Weber, K., \& Struder, H.K. (1997). Metabolic and ergogenic effects of carbohydrate and caffeine beverages in tennis. Journal of Sports Medicine \& Physical Fitness, 37, 258-266. PubMed

Foskett, A., Ali, A., \& Gant, N. (2009). Caffeine enhances cognitive function and skill performance during simulated soccer activity. International Journal of Sport Nutritrion and Exercise Metabolism, 19, 410-423. doi:10.1123/ijsnem.19.4.410

Francis, S., Head, K., Morris, P., \& Macdonald, I. (2006). The effect of flavanol-rich cocoa on the fMRI response to a cognitive task in healthy young people. Journal of Cardiovascular Pharmacology, 47(Suppl. 2), S215-S220. doi:10.1097/00005344-200606001-00018

Fredholm, B.B., Battig, K., Holmen, J., Nehlig, H., \& Zvartau, E. (1999). Actions of caffeine in the brain with special reference to factors that contribute to its widespread use. Pharmacological Reviews, 51, 83-133. PubMed

Ganio, M.S., Armstrong, L.E., Casa, D.J., McDermott, B.P., Lee, E.C., Yamamoto, L.M., ... Lieberman, H.R. (2011). Mild dehydration impairs cognitive performance and mood of men. British Journal of Nutrition, 106(10), 1535-1543.

Geng, J., Dong, J., Ni, H., Lee, M.S., Wu, T., Jiang, K., ... Malouf, R. (2010). Ginseng for cognition. Cochrane Database Systematic Reviews, (12), CD007769.

Giles, G., Mahoney, C., Brunyé, T.T., Gardony, A., Taylor, H., \& Kanarek, R. (2012). Differential cognitive effects of energy drink ingredients: Caffeine, taurine, and glucose. Physiology, Biochemistry and Behavior, 102, 569-577. doi:10.1016/j.pbb.2012.07.004

Glade, M. (2010). Caffeine-Not just a stimulant. Nutrition, 26(10), 932-938. PubMed doi:10.1016/j.nut.2010.08.004

Goble, D., \& Christie, C. (2017). Cognitive, physical and physiological responses of school boy cricketers to a 30-over batting simulation. Journal of Sports Sciences, 35(12), 1148-1154. PubMed doi:10. 1080/02640414.2016.1211731

Gomez-Pinilla, F. (2011). The combined effects of exercise and foods in preventing neurological and cognitive disorders. Preventive Medicine, 52, S75-S80. doi:10.1016/j.ypmed.2011.01.023

Gonçalves, L.S., Painelli, V.S., Yamaguchi, G., Oliveira, L.F., Saunders, B., da Silva, R.P., ... Gualano, B. (2017). Dispelling the myth that habitual caffeine consumption influences the performance response to acute caffeine supplementation. Journal of Applied Physiology (1985), 123(1), 213-220. doi:10.1152/japplphysiol.00260.2017

Gorby, H., Brownawell, A., \& Falk, M. (2010). Do specific dietary constituents and supplements affect mental energy? Review of the evidence. Nutrition Reviews, 68(12), 697-718. PubMed doi:10.1111/ j.1753-4887.2010.00340.x

Graham, T.E. (2001). Caffeine and exercise: Metabolism, endurance and performance. Sports Medicine, 31(11), 785-807. doi:10.2165/ 00007256-200131110-00002

Haskell, C.F., Kennedy, D.O., Wesnes, K.A., Milne, A.L., \& Scholey, A.B. (2007). A double-blind, placebo-controlled, multi-dose 
evaluation of the acute behavioural effects of guaraná in humans. Journal of Psychopharmacology, 21(1), 65-70. PubMed doi:10. 1177/0269881106063815

Hogervorst, E., Bandelow, S., Schmitt, J.A., Jentjens, R., Oliveira, M., Allgrove, J.E., ... Gleeson, M. (2008). Caffeine improves physical and cognitive performance during exhaustive exercise. Medicine \& Science in Sports \& Exercise, 40(10), 1841-1851. PubMed doi:10. 1249/MSS.0b013e31817bb8b7

Holdsworth, D., Cox, P., Kirk, T., Stradling, H., \& Impey, S. (2017). A ketone ester drink increases postexercise muscle glycogen synthesis in humans. Medicine \& Science in Sports \& Exercise, 49(9), 1789-1795. PubMed doi:10.1249/MSS.0000000000001292

Huijgen, B.C., Leemhuis, S., Kok, N.M., Verburgh, L., Oosterlaan, J., Elferink-Gemser, M.T., \& Visscher, C. (2015). Cognitive functions in elite and sub-elite youth soccer players aged 13 to 17 years. PLoS ONE, 10(12), e0144580. PubMed doi:10.1371/journal.pone.0144580

Kempton, M.J., Ettinger, U., Foster, R., Williams, S.C., Calvert, G.A., Hampshire, A., .. S Smith, M.S. (2011). Dehydration affects brain structure and function in healthy adolescents. Human Brain Mapping, 32(1), 71-79. PubMed doi:10.1002/hbm.20999

Kennedy, D.O., Haskell, C.F., Wesnes, K.A., \& Scholey, A.B. (2004). Improved cognitive performance in human volunteers following administration of guarana (Paullinia cupana) extract: Comparison and interaction with Panax ginseng. Pharmacology Biochemistry and Behavior, 79(3), 401-411.

Kennedy, D., Pace, S., Haskell, C., Okello, E.J., Milne, A., \& Scholey, A.B. (2006). Effects of cholinesterase inhibiting sage (Salvia officinalis) on mood, anxiety and performance on a psychological stressor battery. Neuropsychopharmacology, 31, 845-852. PubMed doi:10. 1038/sj.npp.1300907

Krikorian, R., Shidler, M., Dangelo, K., Couch, S., Benoit, S., \& Clegg, D. (2012). Dietary ketosis enhances memory in mild cognitive impairment. Neurobiology and Aging, 33(2), 425.e19-425.e27. doi:10.1016/j.neurobiolaging.2010.10.006

Lamport, D., Pal, D., Moutsiana, C., Field, D., Williams, C., Spencer, J., \& Butler, L.T. (2015). The effect of flavanol-rich cocoa on cerebral perfusion in healthy older adults during conscious resting state: A placebo controlled, crossover, acute trial. Psychopharmacology (Berlin), 232(17), 3227-3234. doi:10.1007/s00213-015-3972-4

Laws, K.R., Sweetnam, H., \& Kondel, T.K. (2012). Is Ginkgo biloba a cognitive enhancer in healthy individuals? A meta-analysis. Human Psychopharmacology, 27, 527-533. doi:10.1002/hup.2259

Lieberman, H.R. (2003). Nutrition, brain function and cognitive performance. Appetite, 40, 245-254. doi:10.1016/S0195-6663(03)00010-2

Liu, Y., Gao, J.H., Liu, H.L., \& Fox, P.T. (2000). The temporal response of the brain after eating revealed by functional MRI. Nature, 405(6790), 1058-1062. PubMed doi:10.1038/35016590

Matsui, T., Soya, S., Okamoto, M., Ichitani, Y., Kawanaka, K., \& Soya, H. (2011). Brain glycogen decreases during prolonged exercise. Journal of Physiology, 589(13), 3383-3393.

Maughan, R.J. (2005). Contamination of dietary supplements and positive drug tests in sport. Journal of Sports Science, 23, 883-889. doi:10. 1080/02640410400023258

Maughan, R.J., Burke, L.M., Dvorak, J., Larson-Meyer, D.E., Peeling, P., Phillips, S.M., ... Engebretsen, L. (2018). Dietary supplements and the high-performance athlete. International Journal of Sport Nutrition and Exercise Metabolism, 28(2). doi:10.1123/ijsnem. 2018-0020

McCall, A.L., Millington, W.R., \& Wurtman, R.J. (1982). Blood-brain barrier transport of caffeine: Dose-related restriction of adenine transport. Life Sciences, 31, 2709-2715. PubMed doi:10.1016/ 0024-3205(82)90715-9
McGregor, S.J., Nicholas, C.W., Lakomy, H.K., \& Williams, C. (1999). The ingestion of intermittent high-intensity shuttle running and fluid ingestion on the performance of a soccer skill. Journal of Sports Science, 17(11), 895-903.

McLellan, T., Caldwell, J., \& Lieberman, H. (2016). A review of caffeine's effects on cognitive, physical and occupational performance. Neuroscience \& Biobehavioral Reviews, 71, 294-312. PubMed doi:10. 1016/j.neubiorev.2016.09.001

Meeusen, R. (2014). Exercise, nutrition and the brain. Sports Medicine, 44(Suppl. 1), 47-56. doi:10.1007/s40279-014-0150-5

Meeusen, R., \& Roelands, B. (2017). Fatigue: Is it all neurochemistry? European Journal of Sport Science, 18(1), 37-46. PubMed doi:10. 1080/17461391.2017.1296890

Meeusen, R., \& Watson, P. (2007). Amino acids and the brain: Do they play a role in "central fatigue"? International Journal of Sports Nutrition and Exercise Metabolism, 17, S37-S46. doi:10.1123/ ijsnem.17.s1.s37

Messier, C. (2004). Glucose improvement of memory: A review. European Journal of Pharmacology, 490(1), 33-57. doi:10.1016/j.ejphar. 2004.02.043

Nehlig, A. (2013). The neuroprotective effects of cocoa flavanol and its influence on cognitive performance. British Journal of Clinical Pharmacology, 75, 716-727. doi:10.1111/j.1365-2125.2012.04378.x

Newsholme, E.A., Acworth, I., \& Blomstrand, E. (1987). Amino acids, brain neurotransmitters and a functional link between muscle and brain that is important in sustained exercise. In: G. Benzi (Ed.), Advances in myochemistry (pp. 127-133). London, UK: John Libbey Eurotext.

Noreen, E., Buckley, J.G., Lewis, S.L., Brandauer, J., \& Stuempfle, K.J. (2013). The effects of an acute dose of Rhodiola rosea on endurance exercise performance. Journal of Strength \& Conditioning Research, 27, 839-847. PubMed doi:10.1519/JSC.0b013e31825d9799

Okada, M., Kiryu, K., Kawata, Y., Mizuno, K., Wada, K., Tasaki, H., \& Kaneko, S. (1997). Determination of the effects of caffeine and carbamazepine on striatal dopamine release by in vivo microdialysis. European Journal of Pharmacology, 321, 181-188. doi:10.1016/ S0014-2999(96)00938-7

Owen, O., Morgan, A., Kemp, H., Sullivan, J., Herrera, M., \& Cahill, G. (1967). Brain metabolism during fasting. Journal of Clinical Investigations, 46(10), 1589-1595. doi:10.1172/JCI105650

Peeling, P., Binnie, M.J., Goods, P.S.R., Sim, M., \& Burke, L.M. (2018). Evidence-based supplements for the enhancement of athletic performance. International Journal of Sport Nutrition and Exercise Metabolism, 28(2). doi:10.1123/ijsnem.2017-0343

Pesce, C., Tessitore, A., Casella, R., Pirritano, M., \& Capranica, L. (2007). Focusing of visual attention at rest and during physical exercise in soccer players. Journal of Sports Sciences, 25, 1259-1270. PubMed doi:10.1080/02640410601040085

Pomportes, L., Brisswalter, J., Casini, L., Hays, A., \& Davranche, K. (2017). Cognitive performance enhancement induced by caffeine, carbohydrate and guarana mouth rinsing during submaximal exercise. Nutrients, 9(6), 589. PubMed doi:10.3390/nu9060589

Porkka-Heiskanen, T. (1999). Adenosine in sleep and wakefulness. Annals of Medicine, 31, 125-129. PubMed doi:10.3109/07853899908998788

Pottier, A., Bouckaert, J., Gilis, W., \& Roels, T., \& Derave, W. (2010). Mouth rinse but not ingestion of a carbohydrate solution improves $1 \mathrm{~h}$ cycle time trial performance. Scandinavian Journal of Medicine \& Science in Sports, 20(1), 105-111. doi:10.1111/j.1600-0838.2008. 00868.x

Rae, C., \& Bröer, S. (2015). Creatine as a booster for human brain function. How might it work? Neurochemistry International, 89, 249-259. PubMed doi:10.1016/j.neuint.2015.08.010 
Rae, C., Scott, R.B., Lee, M., Simpson, J.M., Hines, N., Paul, C., ... Radda, G.K. (2003). Brain bioenergetics and cognitive ability. Developmental Neuroscience, 25(5), 324-331. PubMed doi:10. 1159/000073509

Rawson, E.S., Miles, M.P., \& Larson-Meyer, D.E. (2018). Dietary supplements for health, adaptation, and recovery in athletes. International Journal of Sport Nutrition and Exercise Metabolism, 28(2). doi:10 .1123/ijsnem.2017-0340

Reinmuth, O., Scheinberg, P., \& Bourne, B. (1965). Total cerebral blood flow and metabolism. Archives in Neurology, 12, 49-66. doi:10.1001/ archneur.1965.00460250053007

Ried, K., Sullivan, T., Fakler, P., Frank, O., \& Stocks, N. (2012). Effect of cocoa on blood pressure. Cochrane Database Systematic Reviews, (8), CD008893.

Roelands, B., Hasegawa, H., Watson, P., Piacentini, M.F., Buyse, L., De Schutter, G., \& Meeusen, R.R. (2008). The effects of acute dopamine reuptake inhibition on performance. Medicine \& Science in Sports \& Exercise, 40(5), 879-885. doi:10.1249/MSS.0b013e3181659c4d

Roelands, B., \& Meeusen, R. (2010). Alterations in central fatigue by pharmacological manipulations of neurotransmitters in normal and high ambient temperature. Sports Medicine, 40(3), 229-246. doi:10. 2165/11533670-000000000-00000

Rollo, I., Cole, M., Miller, R., \& Williams, C. (2010). Influence of mouth rinsing a carbohydrate solution on 1-h running performance. Medicine \& Science in Sports \& Exercise, 42(4), 798-804. PubMed doi:10.1249/MSS.0b013e3181bac6e4

Rollo, I., Williams, C., Gant, N., \& Nute, M. (2008). The influence of carbohydrate mouth rinse on self-selected speeds during a 30-min treadmill run. International Journal of Sport Nutrition and Exercise Metabolism, 18(6), 585-600. doi:10.1123/ijsnem.18.6.585

Rollo, I., Williams, C., \& Nevill, M. (2011). Influence of ingesting versus mouth rinsing a carbohydrate solution during a 1-h run. Medicine \& Science in Sports \& Exercise, 43(3), 468-475. PubMed doi:10.1249/ MSS.0b013e3181f1cda3

Sanders, M.A, Shirk, S.D., Burgin, C.J., \& Martin, L.L. (2012). The gargle effect: Rinsing the mouth with glucose enhances self-control. Psychology Sciences, 23(12), 1470-1472. doi:10.1177/0956797612450034

Scholey, A., Tildesley, N., Ballard, C., Wesnes, K.A., Tasker, A., Perry, E.K., \& Kennedy, D.O. (2008). An extract of Salvia (sage) with anticholinesterase properties improves memory and attention in healthy older volunteers. Psychopharmacology, 198, 127-139. PubMed doi:10.1007/s00213-008-1101-3

Shukitt-Hale, B., Lau, F.C., Carey, A.N., Galli, R.L., Spangler, E.L., Ingram, D.K., \& Joseph, J.A. (2008). Blueberry polyphenols attenuate kainic acid-induced decrements in cognition and alter inflammatory gene expression in rat hippocampus. Nutritional Neuroscience, 11(4), 172-182. doi:10.1179/147683008X301487

Smith, I., Williamson, E.M., Putnam, S., Farrimond, J., \& Whalley, B.J. (2014). Effects and mechanisms of ginseng and ginsenosides on cognition. Nutritional Reviews, 72, 319-333. doi:10.1111/nure.12099

Somerville, V., Bringans, C., \& Braakhuis, A. (2017). Polyphenols and performance: A systematic review and meta-analysis. Sports Medicine, Aug, 47(8), 1589-1599. doi:10.1007/s40279017-0675-5

Stevenson, E., Hayes, P., \& Allison, S. (2009). The effect of a carbohydrate-caffeine sports drink on simulated golf performance. Applied Physiology, Nutrition and Metabolism, 2009, 34(4), 681-688. doi:10. 1139/H09-057

Stuart, G.R., Hopkins, W.G., Cook, C., \& Cairns, S.P. (2005). Multiple effects of caffeine on simulated high-intensity team-sport performance. Medicine \& Science in Sports \& Exercise, 37, 1998-2005. PubMed doi:10.1249/01.mss.0000177216.21847.8a
Tan, M., Yu, J., Tan, C., Wang, H., Meng, X., Wang, C., ... Tan, L. (2015). Efficacy and adverse effects of ginkgo biloba for cognitive impairment and dementia: A systematic review and meta-analysis. Journal of Alzheimers Disease, 43(2), 589-603.

Thompson, C., Wylie, L.J., Fulford, J., Kelly, J., Black, M.I., McDonagh, S.T., .. Jones, A.M. (2015). Dietary nitrate improves sprint performance and cognitive function during prolonged intermittent exercise. European Journal of Applied Physiology, 115(9), 1825-1834. PubMed doi:10.1007/s00421-015-3166-0

Tildesley, N., Kennedy, D., Perry, E., Ballard, C.G., Savelev, S., Wesnes, K.A., \& Scholey, A.B. (2003). Salvia lavandulaefolia (Spanish sage) enhances memory in healthy young volunteers. Pharmacology, Biochemistry and Behavior, 75, 669-674. PubMed doi:10.1016/ S0091-3057(03)00122-9

Tildesley, N., Kennedy, D., Perry, E., Ballard, C.G., Wesnes, K.A., \& Scholey, A.B. (2005). Positive modulation of mood and cognitive performance following administration of acute doses of Salvia lavandulaefolia essential oil to healthy young volunteers. Physiology and Behavior, 83, 699-709. PubMed doi:10.1016/j.physbeh.2004.09.010

Tumilty, L., Davison, G., Beckmann, M., \& Thatcher, R. (2011). Oral tyrosine supplementation improves exercise capacity in the heat. European Journal of Applied Physiology, 111, 2941-2950. doi:10. 1007/s00421-011-1921-4

Tumilty, L., Davison, G., Beckmann, M., \& Thatcher, R. (2012). Acute oral tyrosine administration does not improve exercise performance in the heat in man. Proceedings of Physiological Society, 26, PC57.

Van Hall, G., Raaymakers, J.S., Saris, W.H., \& Wagenmakers, A.J. (1995). Ingestion of branched-chain amino acids and tryptophan during sustained exercise in man: Failure to affect performance. Journal of Physiology, 486, 789-794. PubMed doi:10.1113/ jphysiol.1995.sp020854

Vauzour, D. (2012). Dietary polyphenols as modulators of brain functions: Biological actions and molecular mechanisms underpinning their beneficial effects. Oxidative Medicine and Cell Longevitv, 2012, 914273.

Veasey, R., Haskell-Ramsay, C., Kennedy, D., Wishart, K., Maggini, S., Fuchs, C., \& Stevenson, E. (2015). The effects of supplementation with a vitamin and mineral complex with guaraná prior to fasted exercise on affect, exertion, cognitive performance, and substrate metabolism: A randomized controlled trial. Nutrients, 7(8), 6109-6127. PubMed doi:10.3390/nu7085272

Volek, J., Noakes, T., \& Phinney, S. (2015). Rethinking fat as a fuel for endurance exercise. European Journal of Sport Sciences, 15(1), 13-20. doi:10.1080/17461391.2014.959564

Warren, G.L., Park, N.D., Maresca, R.D., McKibans, K.I., \& MillardStafford, M.L. (2010). Effect of caffeine ingestion on muscular strength and endurance: A meta-analysis. Medicine \& Science in Sports \& Exercise, 42(7), 1375-1387. PubMed doi:10.1249/MSS. 0b013e3181cabbd8

Watson, P., Black, K.E., Clark, S.C., \& Maughan, R.J. (2006). Exercise in the heat: Effect of fluid ingestion on blood-brain barrier permeability. Medicine \& Science in Sports \& Exercise, 38(12), 2118-2124. PubMed doi:10.1249/01.mss.0000235356.31932.0a

Watson, P., Enever, S., Page, A., Stockwell, J., \& Maughan, R.J. (2012). Tyrosine supplementation does not influence the capacity to perform prolonged exercise in a warm environment. International Journal of Sport Nutrition and Exercise Metabolism, 22, 363-373. PubMed doi:10.1123/ijsnem.22.5.363

Watson, P., Hasegawa, H., Roelands, B., Piacentini, M.F., Looverie, R., \& Meeusen, R. (2005). Acute dopamine/noradrenaline reuptake inhibition enhances human exercise performance in warm, but not temperate conditions. Journal of Physiology, 565, 873-883. PubMed doi:10. 1113/jphysiol.2004.079202 
Watson, P., Nichols, D., \& Cordery, P. (2014). Mouth rinsing with a carbohydrate solution does not influence cycle time trial performance in the heat. Journal of Applied Physiology Nutrition and Metabolism, 39(9), 1064-1069. doi:10.1139/apnm-2013-0413

Watson, P., Shirreffs, S.M., \& Maughan, R.J. (2004). The effect of acute branched-chain amino acid supplementation on prolonged exercise capacity in a warm environment. European Journal of Applied Physiology, 93(3), 306-314. PubMed doi:10.1007/s00421-004-1206-2

Wender, R., Brown, A.M., Fern, R, Swanson, R.A., Farrell, K., \& Ransom, B.R. (2000). Astrocytic glycogen influences axon function and survival during glucose deprivation in central white matter. Journal of Neuroscience, 20, 6804-6810. PubMed
Whitham, M., \& McKinney, J. (2007). Effect of a carbohydrate mouthwash on running time trial performance. Journal of Sport Science, 25(12), 1385-1392. doi:10.1080/02640410601113676

Wightman, E.L., Haskell-Ramsay, C.F., Thompson, K.G., Blackwell, J.R., Winyard, P.G., Forster, J., ... Kennedy, D.O. (2015). Dietary nitrate modulates cerebral blood flow parameters and cognitive performance in humans: A double-blind, placebo-controlled, crossover investigation. Physiology \& Behavior, 149, 149-158. doi:10. 1016/j.physbeh.2015.05.035

Williams, C., \& Rollo, I. (2015). Carbohydrate nutrition and team sport performance. Sports Medicine, 45(Suppl. 1), 13-22. doi:10.1007/ s40279-015-0399-3 